\title{
Growth of Time-Dependent Strain in Reinforced Cement Concrete and Pre-stressed Concrete Flexural Members
}

\author{
Swarup Rn. Debbarma ${ }^{1), *}$, and Showmen Saha ${ }^{2)}$
}

(Received February 13, 2012, Accepted May 22, 2012, Published online July 1, 2012)

\begin{abstract}
This paper presents the differences in growth of time-dependent strain values in reinforced cement concrete (RCC) and pre-stressed concrete (PSC) flexural members through experiment. It was observed that at any particular age, the time-dependent strain values were less in RCC beams than in PSC beams of identical size and grade of concrete. Variables considered in the study were percentage area of reinforcement, span of members for RCC beams and eccentricity of applied pre-stress force for PSC beams. In RCC beams the time-dependent strain values increases with reduction in percentage area of reinforcement and in PSC beams eccentricity directly influences the growth of time-dependent strain. With increase in age, a non-uniform strain develops across the depth of beams which influence the growth of concave curvature in RCC beams and convex curvature in PSC beams. The experimentally obtained strain values were compared with predicted strain values of similar size and grade of plane concrete (PC) beam using ACI 318 Model Code and found more than RCC beams but less than PSC beams.
\end{abstract}

Keywords: time-dependent strain, creep, shrinkage, pre-stress concrete, reinforced concrete, flexural member.

\section{Introduction}

In reinforced and pre-stressed concrete structures the growth of time dependent effects due to creep and shrinkage is complicated and depends upon, presence of steel reinforcement and/or pre-stressing steel, amount of pre-stress force, inherent non-elastic properties of concrete the construction stages of concrete, the continuous re-distribution of stress and the effects of external restraints and supports. Under restrain conditions, shrinkage is always associated with creep which relieves the stresses induced by shrinkage. In general, shrinkage and creep are taken into account of long-term deformation and pre-stress loss analysis of concrete structure (Zamblauskaite et al. 2005). Considering long term effect, shrinkage and creep may significantly reduce crack resistance and increase deformation of reinforced concrete structures subjected to short term loading (Bischoff 2001; Sato et al. 2007).

Volumetric changes of hardened concrete can results in cracking (Weiss 1999). He had compared the development of time dependent strength (cracking resistance) with the growth of time dependent residual stress. If strength and residual stress development are plotted as shown in Fig. 1, it is likely that the specimen will crack when these two lines

\footnotetext{
${ }^{1)}$ CSIR-Central Mechanical Engineering Research Institute, Durgapur 713209, India.

*Corresponding Author; E-mail: debbarma@yahoo.com

${ }^{2)}$ Civil Engineering Department, National Institute of Technology, Durgapur 713209, India.

Copyright ( $\odot$ The Author(s) 2012. This article is published with open access at Springerlink.com
}

intersects. If the strength of concrete is always greater than the developed stresses, no cracking will occurs in the concrete section.

Shrinkage of an isolated plain concrete member would merely shorten it without causing camber (Gribniak et al. 2007). Reinforcement embedded in a concrete member provides restrain to growth of shrinkage strain leading to compressive stress in reinforcement and tensile stress in concrete. If reinforcement is not placed symmetrically along the cross-section, the strain due to shrinkage of concrete causes non-uniform stress and strain distribution within the height of the section. The maximum tensile stress appears in the extreme concrete fiber, close to the larger concentration of reinforcement area. Zuanfeng et al. (2011) presented a formula to determine the influence coefficients of steels on creep and shrinkage of RCC specimen which was found to be a good agreement between calculated values and measured field data. Gribniak et al. (2008) investigated numerically the influence of shrinkage on behavior of reinforced concrete beams and compared with test data reported in literature.

Objective of this paper is to present the experimental findings of time-dependent strain growth in reinforced and pre-stressed concrete beams. In reinforced concrete beams, the influence of percentage area of reinforcements and its span, in growth of time-dependent strain were investigated. The influence of pre-stress force and its eccentricity in growth of time-dependent strain in pre-stressed concrete beams were investigated and presented. The experimental values were compared with predicted strain values for plane concrete beam using prediction model code for same size of beam. The growth of non-uniform strain across the depth of 


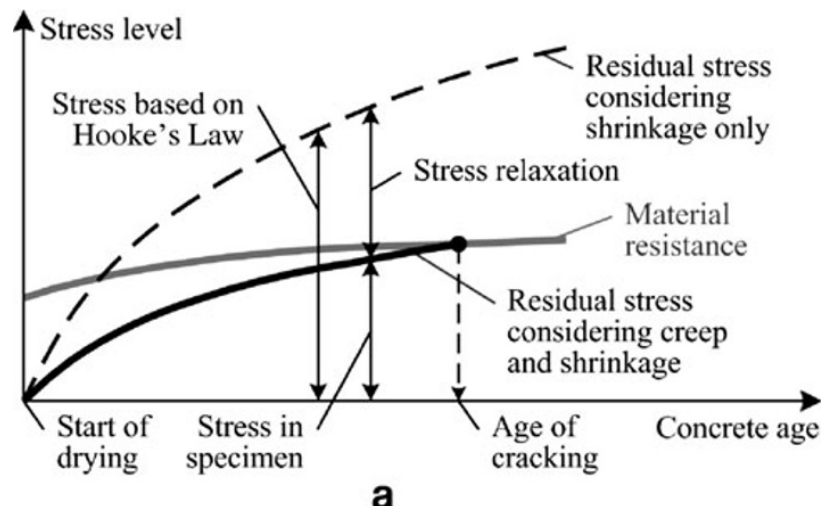

Fig. 1 Stresses in a restrained concrete member due to shrinkage and associated creep.

the experimental beams and its effects in change of beam axis profile is also presented in this paper.

\section{Experimental Program}

Ten numbers of laboratory scale concrete beams were designed and constructed for the experiment. Out of ten, six were reinforced cement concrete (RCC) beams and other four were reinforced pre-stressed concrete (PSC) beams. All the beams were of identical cross sectional dimensions, with similar grade of concrete. The variables were percentage area of reinforcement in tension zone, span, and age of concrete for RCC beams. The influence of pre-stress force in the growth of time-dependent strain was investigated in PSC beams with two different eccentricity $(e)$ of applied prestress force from its centrodial axis. Vibrating Wire (V.W) strain gauges were embedded in length direction at mid span along the upper and bottom layer of reinforcement of each beam to monitor the growth of strain at regular interval of days. For every identical beam specimens the results were almost same, so average values were considered for analysis and presented in this paper. The growth of time dependent strain in plane concrete (PC) beam of similar cross-sectional area, span, and grade of concrete was determined using prediction model code ACI 318 using Midas Civil software for comparison.

\subsection{Materials}

Mix proportion of concrete is shown in Table 1. Average 28 days compressive strength of the concrete, using cube specimen of size $150 \times 150 \times 150 \mathrm{~mm}^{3}$ was $35.3 \mathrm{MPa}$. Modulus of elasticity of concrete was $29.7 \mathrm{GPa}$ and flexural strength was $4.16 \mathrm{MPa}$. The types of reinforcing materials used in both the test beams were $8 \mathrm{~mm}$ diameter high yield strength deformed bars conforming to IS:1786, grade Fe415. chemical composition of Fe415 steel bars are shown in

Table 2 Chemical composition of Fe415 bars.

\begin{tabular}{c|c|c|c|c}
\hline Elements & $\mathrm{C}$ & $\mathrm{Mg}$ & $\mathrm{S}$ & $\mathrm{P}$ \\
\hline \hline $\begin{array}{c}\text { Max. \% by } \\
\text { weight }\end{array}$ & 0.30 & 0.60 & 0.06 & 0.06 \\
\hline
\end{tabular}

Table 1 Mix proportion of concrete in $\mathrm{kg} / \mathrm{m}^{3}$.

\begin{tabular}{c|c|c|c|c}
\hline Cement & Water & Sand & $\begin{array}{c}15 \mathrm{~mm} \\
\text { aggregate }\end{array}$ & $\begin{array}{c}10 \mathrm{~mm} \\
\text { aggregate }\end{array}$ \\
\hline \hline 400 & 172 & 635 & 619 & 564 \\
\hline
\end{tabular}

Table 2. Modulus of elasticity of steel was $200 \mathrm{kN} / \mathrm{mm}^{2}$, bulk density $7,860 \mathrm{~kg} / \mathrm{m}^{3}$, yield stress $415 \mathrm{MPa}$, ultimate tensile strength $485 \mathrm{MPa}$ and $14.5 \%$ elongation.

High tensile steel of diameter $4 \mathrm{~mm}$, conforming to IS:1343, having characteristic strength $1,750 \mathrm{~N} / \mathrm{mm}^{2}$ was used as a pre-stressing wires. The pre-stress force of $17 \mathrm{KN}$ was imposed on PSC beams through three nos of prestressing wires of $4 \mathrm{~mm}$ diameter at an eccentricity of 75 and $175 \mathrm{~mm}$ from the top fiber of the PSC beams.

\subsection{Experimental Beams, Testing Apparatus and Procedure}

Steel molds with open end blocks were used for casting of beams. Vibrating nozzles were used for proper compaction of machine mixed concrete in the steel molds. All the experimental beams were cured under moist condition for 28 days before putting in simply supported condition. Details of the experimental beams and slabs are shown in Fig. 2 and in Tables 3 and 4. Sample photographs of experimental beams before and after concreting are shown in Fig. 3. In PSC beams, the pre-stress force of $17 \mathrm{kN}$ was applied using hydraulic pumps and jacks. In RCC beams, $\mathrm{B} 2 \mathrm{Fe} 2$ three numbers of high tensile steel wires were passed through the section and hold in position without application of pre-stress force. V.W embedment strain gauges fixed inside the beams provided frequency and temperature data through read out unit. In V.W strain gauges, plucking the wire with electromagnetic coils and measuring the frequency of the resulting vibration provides the development of tension in the wire. Measured frequency values were converted into strain values by multiplying gauge factors and also compensating for atmospheric temperature variations. Growth of strain and corresponding temperature, at mid span were measured along top and bottom layer of reinforcements at regular interval of days.

\section{Test Results and Discussion}

Development of time-dependent strain in RCC and PSC experimental beams, up to concrete age of 300 days and 150 days, respectively, are presented and discussed in this paper. In RCC beam the load was self weight of the beam and in PSC beam the load was self weight plus axial pre-stress force.

\subsection{Effect of Percentage Area of Reinforcement}

During early days of concrete, the growth of strain was negative or tensile in all the RCC beams due to heat of hydration of cement. Growth of compressive strain was observed in sections above and below neutral axis (N.A) of RCC beams after placing in simply supported condition and it increases with its age. The growth of strain in RCC beams, 


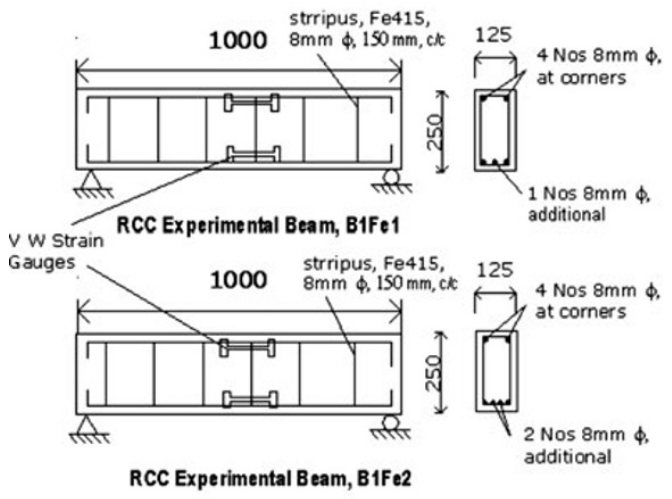

Fig. 2 Elevation and cross-section of experimental beams B2Fe2 and PSBFe2.

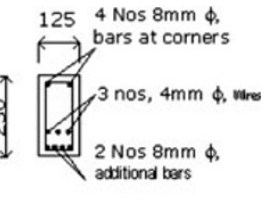

RCC Experimental Beam, B2Fe2

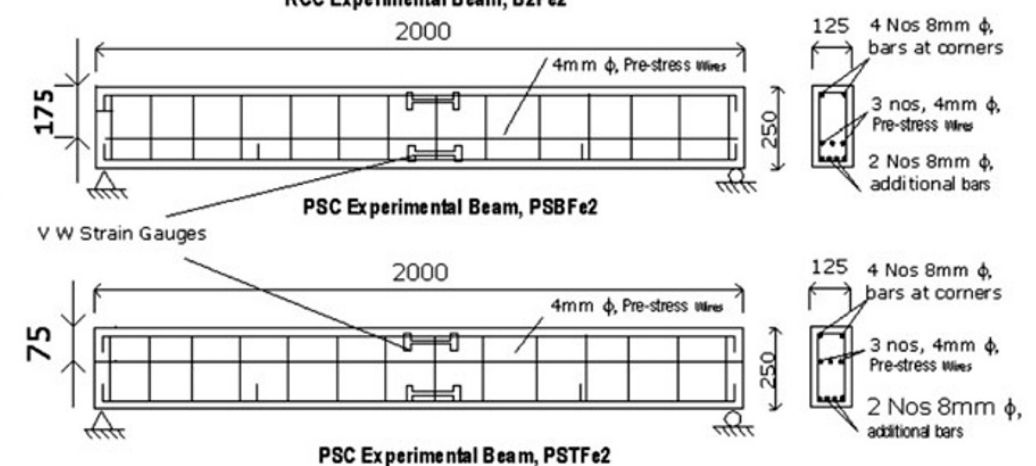

Table 3 Identity and parameters of RCC beams.

\begin{tabular}{c|c|c|c|c}
\hline Identity & $\begin{array}{c}\text { No. of } \\
\text { sample }\end{array}$ & Span (mm) & $\begin{array}{c}\% \text { Area } \\
\text { of } A_{\text {sc }}\end{array}$ & $\begin{array}{c}\% \text { Area } \\
\text { of } A_{\text {st }}\end{array}$ \\
\hline \hline B1Fe1 & 02 & 1,000 & 0.32 & 0.48 \\
\hline B1Fe2 & 02 & 1,000 & 0.32 & 0.64 \\
\hline B2Fe2 & 02 & 2,000 & 0.32 & 0.64 \\
\hline
\end{tabular}

Table 4 Identity and parameters of PSC beams.

\begin{tabular}{c|c|c|c|c|c}
\hline Identity & $\begin{array}{c}\text { No. of } \\
\text { sample }\end{array}$ & $\begin{array}{c}\text { Span } \\
(\mathrm{mm})\end{array}$ & $\begin{array}{c}\text { \% Area } \\
\text { of }\left(\mathrm{A}_{\mathrm{sc}}\right)\end{array}$ & $\begin{array}{c}\% \text { Area } \\
\text { of }\left(\mathrm{A}_{\text {st }}\right)\end{array}$ & e (mm) \\
\hline \hline PSTFe2 & 02 & 2,000 & 0.32 & 0.64 & 25 \\
\hline PSBFe2 & 02 & 2,000 & 0.32 & 0.64 & 125 \\
\hline
\end{tabular}

$\mathrm{B} 1 \mathrm{Fe} 1$, and $\mathrm{B} 1 \mathrm{Fe} 2$ of equal span and sectional area are plotted in Fig. 4. The only difference between the two beams was percentage area of reinforcement present in its tension zone $\left(A_{s t}\right)$. It was observed that with increase in age of concrete, the growth of strain increases in both the beams, having some difference between them. At any particular age of concrete, the beams with lesser percentage area of reinforcement in tension zone exhibits more growth of strain than in beams with more percentage area of reinforcement. At 300 days age of concrete the growth of average timedependent strain in beams $\mathrm{B} 1 \mathrm{Fe} 2$ was $21 \%$ less than in beams $\mathrm{B} 1 \mathrm{Fe} 1$, due to presence of $0.16 \%$ more area of steel reinforcement.

\subsection{Effect of Span of Flexural Members}

The growth of time-dependent strain in section above and below N.A, at mid span of RCC beams, B1Fe2, and B2Fe2 are plotted in Fig. 5. The growth of strain was observed more in larger span beams than in smaller span beams, made of similar cross-section, percentage area of reinforcement and grade of concrete. In simply supported flexural members with increase in span, the growth of instantaneous deflection and strain at mid span increases. With age of concrete this influences the growth of more time-dependent strain. From the test results it was observed that, the growth of timedependent strain increased by $47 \%$ due to increase in span to double with same section and percentage area of reinforcement. In both the beams the growth of strain was more in section above N.A than in section below N.A due to presence of lesser percentage area of reinforcement in compression zone. The differences in strain growth between section above and below N.A were more in beams of larger span than in beams of smaller span.

\subsection{Effect of Ambient Temperature and Humidity}

The changes in atmospheric temperature directly influence the growth rate ratio of creep and shrinkage and also affect the rate of aging of concrete, ACI 209R-92 (ACI, 1992). The growth of time-dependent average strain across the depth of
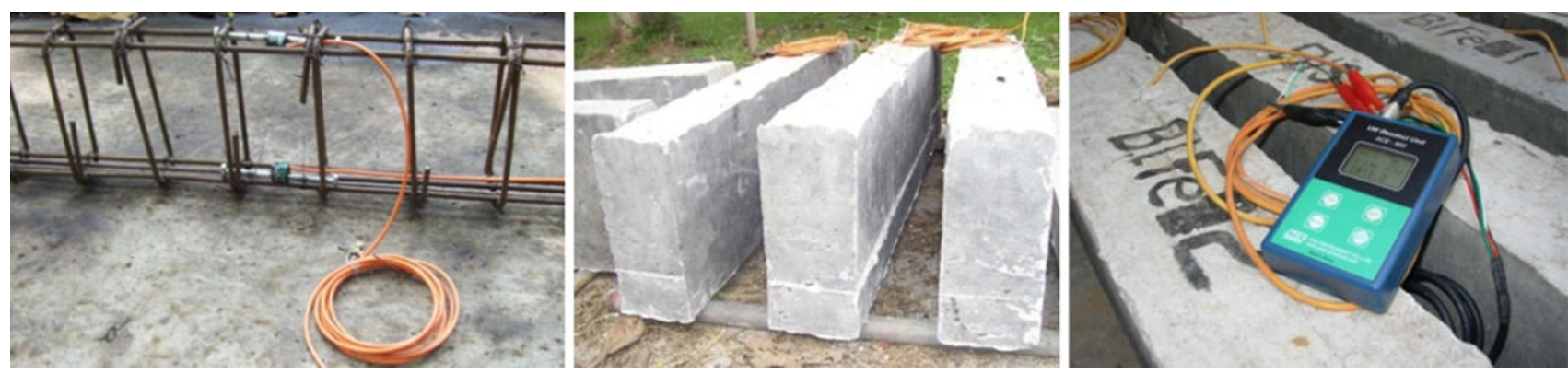

Fig. 3 Experimental beams with strain gauges before and after concreting. 


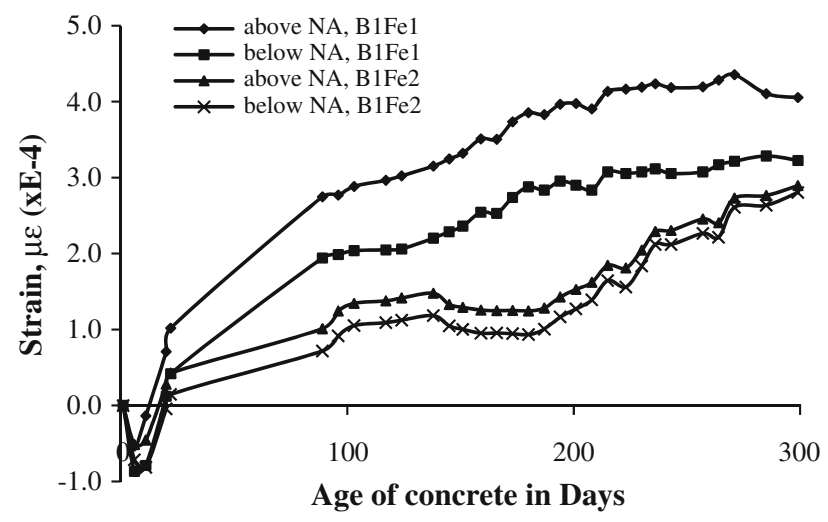

Fig. 4 Growth of strain at mid span section of RCC beams with different percentage area of reinforcement.

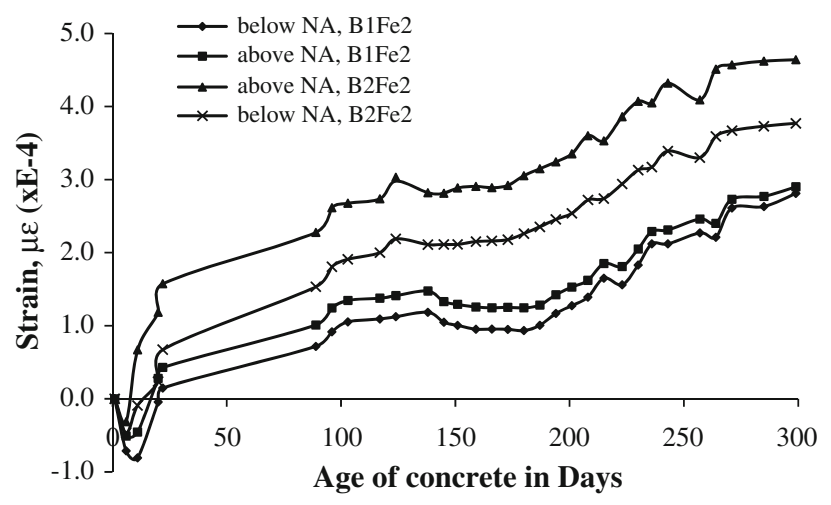

Fig. 5 Growth of strain at mid span section of RCC beams of different span.

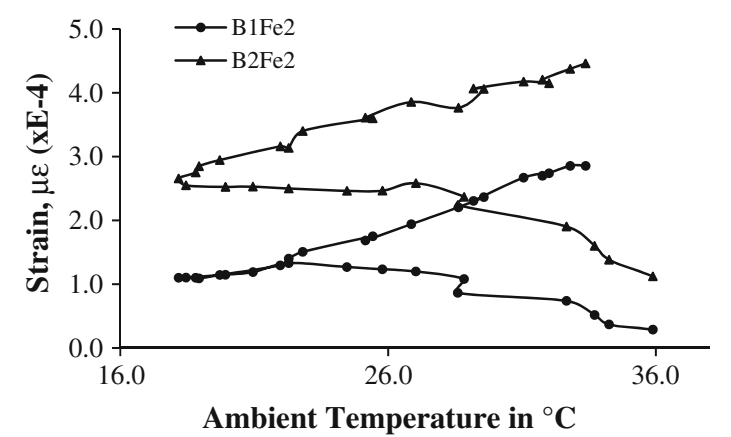

Fig. 6 Growth of strain in RCC beams at different ambient temperature.

RCC and PSC beams at different ambient temperature are plotted in Figs. 6, 7, respectively. From the graphs it can be observed that, the growth rate of time-dependent strain was higher in all the beams during summer days than in winter days. Increase in humidity in atmosphere during rainy days, causes decrease in growth rate of strain in both RCC and PSC beams. It was also observed that, at any particular age with increase in humidity decreases the accumulated timedependent strain values of beams.

\subsection{Effect of Pre-stress in Growth of Time- Dependent Strain}

The growth of time-dependent strain along top and bottom layer of reinforcements in $\mathrm{RCC}$ beams $(\mathrm{B} 2 \mathrm{Fe} 2)$ and $\mathrm{PSC}$ beams $(\mathrm{PSBF} 2)$ of similar sectional area and span are

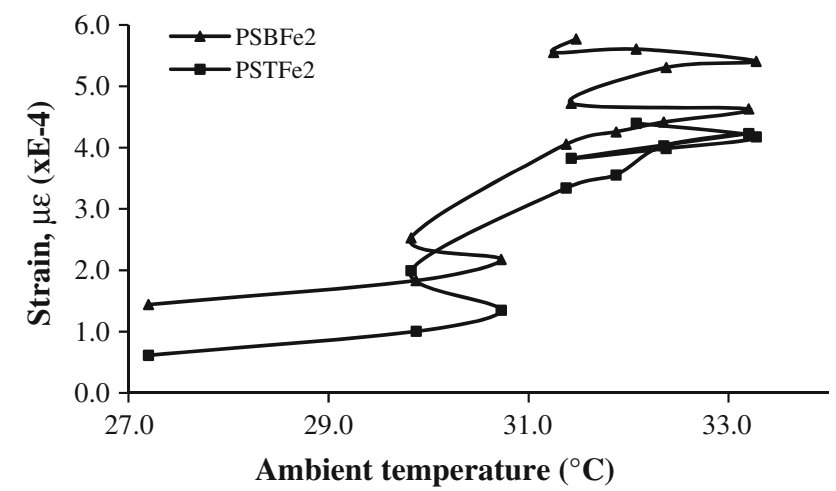

Fig. 7 Growth of strain in PSC beams at different ambient temperature.

plotted in Fig. 8 for comparison. At any particular age of concrete the growth of time-dependent strain was observed more in PSC beams than in RCC beams made with similar grade of concrete. The pattern of strain growth with age of concrete was similar in both the sections, along top and bottom layer of reinforcement in RCC and PSC beams, having some incremental difference between them. In PSC beams the strain growth was observed more along bottom layer of reinforcement than along top layer of reinforcement, due to presence of line of action of pre-stress force nearer to that section. Pre-stress force, increases growth of timedependent strain by suppressing the resistance from reinforcement as in RCC beams. In RCC beams $\mathrm{B} 2 \mathrm{Fe} 2$, the differences of $0.32 \%$ area of steel reinforcement, between sections above and below N.A, exhibits $39 \%$ difference in strain growth at concrete age of 150 days. In reinforced PSC beams PSBFe2, this difference of strain growth reduced to $9 \%$ due to presence of axial pre-stress force along its length at the same age of concrete.

The strain values obtained at particular age, from sections along top and bottom layer of reinforcements were averaged for comparison between RCC and PSC beams. It was observed that, in PSC beams the pre-stress force of $450 \mathrm{~N} / \mathrm{mm}^{2}$ applied at constant eccentricity of $125 \mathrm{~mm}$ below centrodial axis, increases growth of time-dependent strain by $73 \%$ than in RCC beams at 150 days age of concrete.

\subsection{Effect of Eccentricity of Pre-stress Force in Growth of Time-Dependent Strain}

The average strain values obtained across the depth of reinforced PSC beams PSBFe2 and PSTFe2 with age of concrete are plotted in Fig. 9 for comparison. The differences in growth of time-dependent strain in two PSC beams of identical dimensions, specifications and with same value of pre-stress force was mainly due to differences in eccentricity of applied pre-stress force. At any particular age of concrete, the growth of strain was observed more in PSC beams with more eccentric value of applied pre-stress force. This difference in strain growth further increases with increase in age of concrete. At 150 days age of concrete it was observed that, with increase in eccentricity of pre-stress force by five times below centrodial axis, the growth of timedependent strain increased by $35 \%$. 


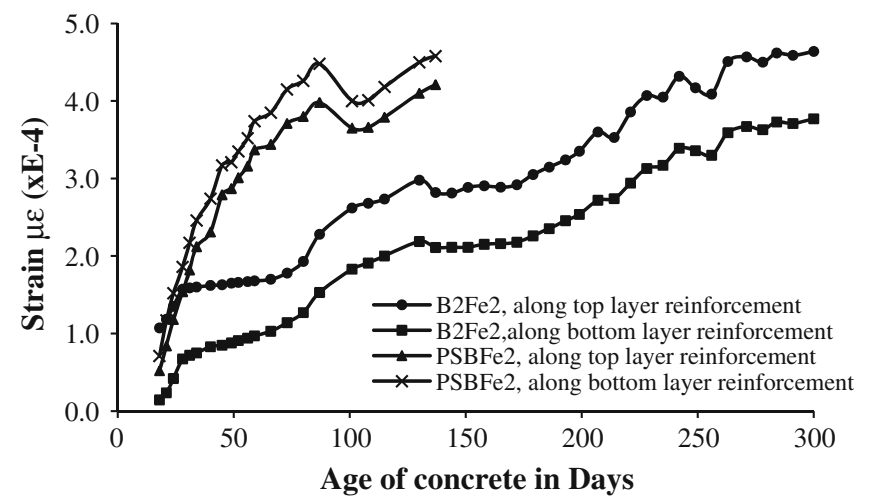

Fig. 8 Growth of time-dependent strain in RCC and PSC beams.

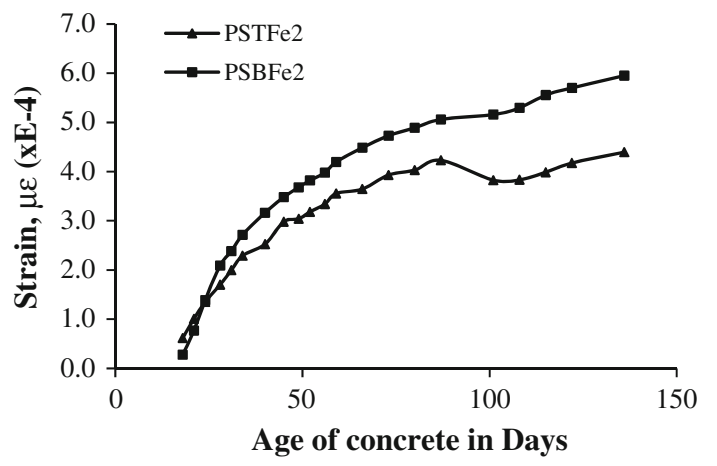

Fig. 9 Growth of strain in reinforced PSC beams with different eccentricity of pre-stress.

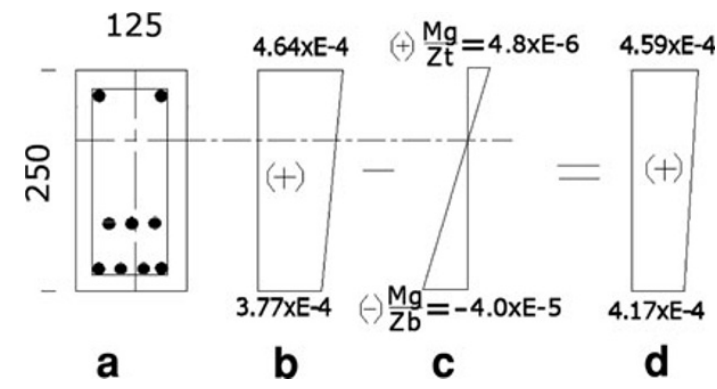

Fig. 10 a Cross section of RCC beam B2Fe2, b experimental strain values at 300 days, c calculated strain due to D.L, $\mathbf{d}$ time-dependent strain of concrete.

\subsection{Growth of Non-uniform Strain Across the Depth of Beam}

The growth of time-dependent strain values were obtained from the experimental results after deduction of instantaneous strain values due to imposed load. The instantaneous strain values of RCC and PSC beams were determined using standard bending theory of flexural members. The timedependent strain values in $\mathrm{B} 2 \mathrm{Fe} 2$, at 300 days age of concrete and in PSBFe2, at 150 days age of concrete are shown in Figs. 10, 11, respectively. In RCC beams, growths of time-dependent strain were observed more in section above than in section below N.A. Presence of lesser percentage area of reinforcement in section above N.A $\left(\mathrm{A}_{\mathrm{sc}}\right)$, caused growth of more strain. Development of this non-uniform strain across its depth, under freely supported condition will influence the deformation in concave curvature of beam axis which further increases with increase in its age, as shown in Fig. 12a. In PSC beams, growths of time-dependent strain were observed more in section below than in section above centrodial axis. The axial pre-stress force applied in section below centrodial axis causes, growth of more strain than in section above centrodial axis. This developed non-uniform strain across its depth and under freely supported condition and will results in convex curvature of beam axis, which further increases with increase in its age, as shown in Fig. 12b.

\section{Predicted Time-Dependent Strain in Plane Concrete (PC) Beam}

The growth of time-dependent strain with age of concrete in the PC beam of cross-sectional area $125 \times 250 \mathrm{~mm}^{2}$ and length 2,000 $\mathrm{mm}$ (same as experimental beam) was determined using MIDAS Civil software. The model code used for prediction of shrinkage and creep strain was ACI 318 (ACI, 2005) along its length up to 1,000 days age of concrete, and shown in Fig. 13. Creep strain was determined for sustained load due to self weight only. The growth of strain in plane concrete beam was uniform across its depth without any restrain or influence of reinforcement or pre-stress force. This will causes no change in the curvature of beam axis with increase in its age (Table 5).

During early days, the predicted values for creep and shrinkage strain were rapid but with increase in age, the rate of growth of strain reduces. The predicted creep and shrinkage strain values at 10,000 days age of concrete are shown in Table 6. Shrinkage strain was positive or compressive in nature and it results in contraction in size of beam. The creep strain, under sustained dead load, was negative or tensile in nature and it results in expansion of its size. The combined effects of creep and shrinkage strain in PC beam were compressive in nature.

\subsection{Comparison of Strain Growth in RCC, PSC, and PC Beams}

Growth of average time-dependent strain values in RCC beam $\mathrm{B} 2 \mathrm{Fe} 2$ and PSC beam PSBFe2 are plotted in Fig. 14 with predicted strain values for P.C beam as per ACI 318 model code. The predicted strain values for PC beam were more than the experimentally obtained strain values for RCC beams but less than the PSC beams. This difference in growth of strain was due to restrain from the reinforcement present in RCC beam and influence of pre-stress force present in the PSC beam.

In RCC beams of $2.0 \mathrm{~m}$ span, by providing $1.01 \%$ area of steel reinforcement, the reduction in growth of time-dependent strain was $12.9 \%$ in comparison to $\mathrm{PC}$ beam at 300 days age of concrete. In PSC beams of $2.0 \mathrm{~m}$ span, with applied pre-stress force of $450 \mathrm{~N} / \mathrm{mm}^{2}$ at eccentricity of $125 \mathrm{~mm}$ below centrodial axis, increased the growth of 


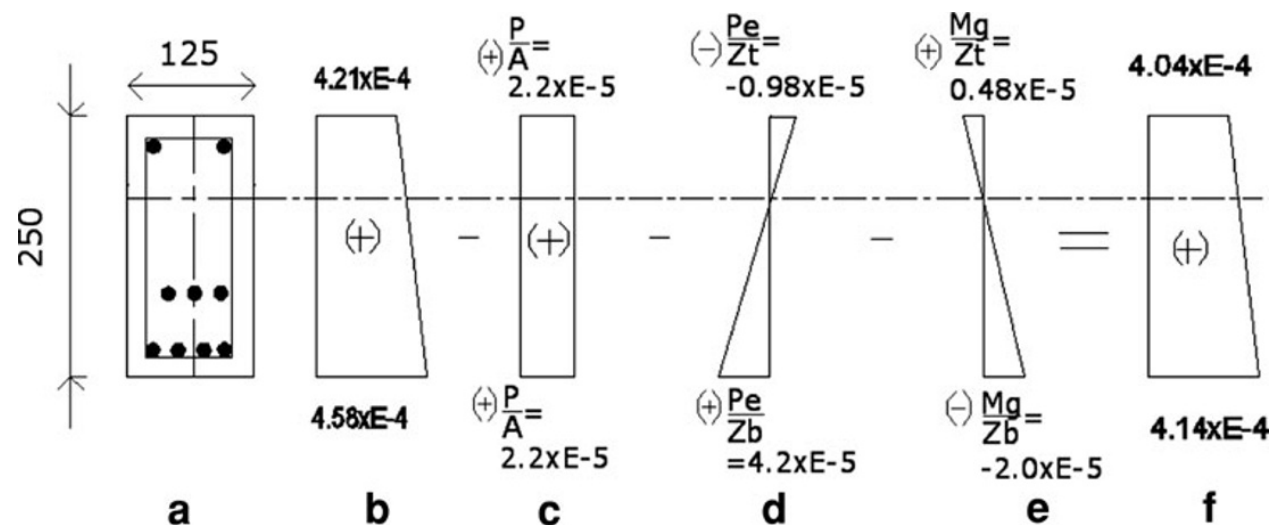

Fig. 11 a Cross section of PSC beam PSBFe2, b experimental strain values at 150 days, $\mathbf{c}$ direct strain due to pre-stress, d bending strain due to pre-stress, e Self weight strain, $\mathbf{f}$ time-dependent strain.

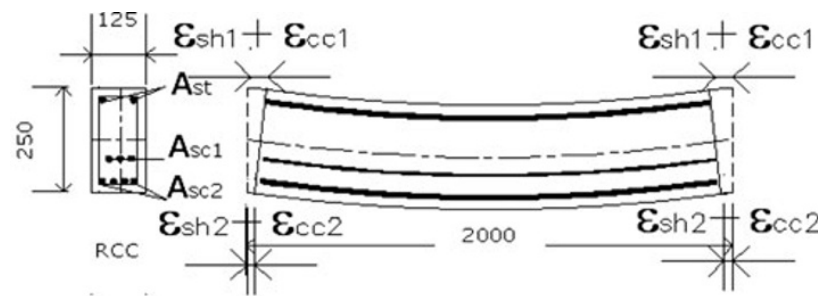

a Reinforced cement concrete Beam

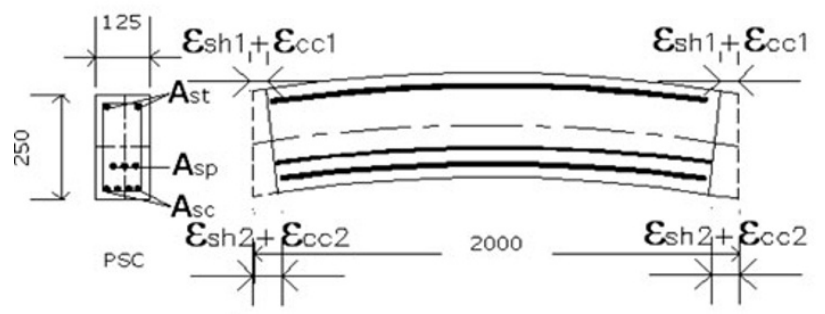

b Pre-stressed Concrete Beam

Fig. 12 Change in beam axis due to growth of non-uniform time-dependent strain.

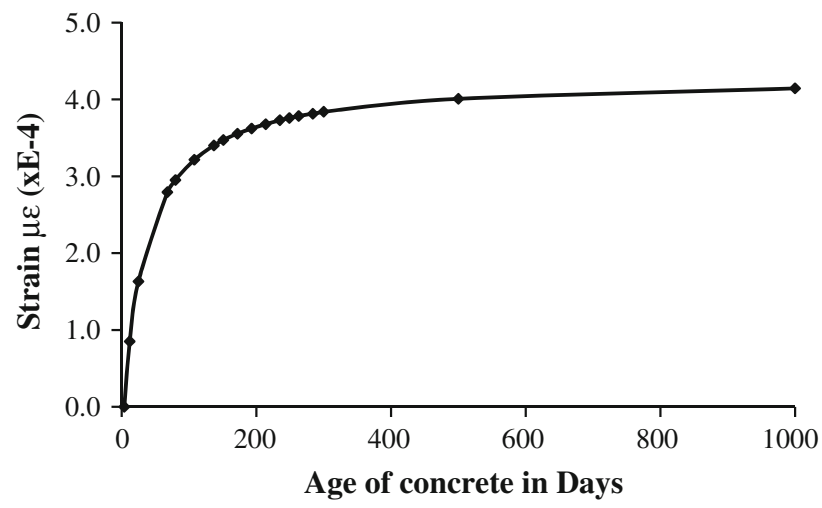

Fig. 13 Predicted time-dependent strain in PC beam. time-dependent strain by $10 \%$ in comparison to $\mathrm{PC}$ beam and $62 \%$ in comparison to RCC beam at 150 days age of concrete.

This will also affects the occurrence of ultimate shrinkage and creep strain values of concrete. In PSC members the occurrence of creep and shrinkage of concrete and losses of pre-stress force are inter-related. The two ends of the prestressing tendons in PSC beam constantly move towards each other because of creep and shrinkage of concrete, thereby reducing the tensile stress in the tendon and increasing the growth of creep and shrinkage strain.

Table 6 Predicted time-dependent strain values.

\begin{tabular}{c|c|c}
\hline Shrinkage strain & Creep strain & Total strain \\
\hline \hline $4.33 \times \mathrm{E}-4$ & $-5.85 \times \mathrm{E}-6$ & $4.27 \times \mathrm{E}-4$ \\
\hline
\end{tabular}

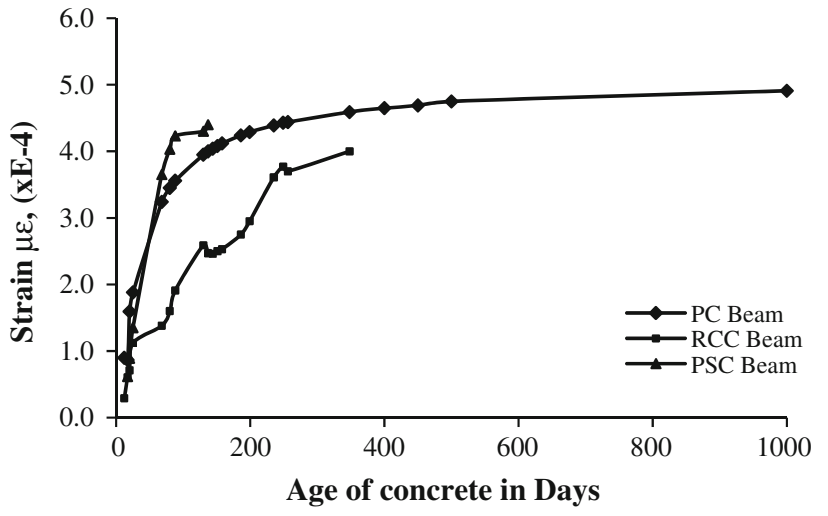

Fig. 14 Growth of time-dependent strain in RCC, PSC, and PC beam.

Table 5 Strain values in RCC and PSC beams at different age of concrete.

\begin{tabular}{c|c|c|c|c|c|c|c}
\hline \multirow{2}{*}{ S1. No } & Age of conc & \multicolumn{3}{|c|}{ Strain growth test beam B2Fe2 } & \multicolumn{3}{|c}{ Strain growth test beam PSBFe2 } \\
\cline { 3 - 8 } & & $\begin{array}{c}\text { Above N.A } \\
(\times \mathrm{E}-4)\end{array}$ & $\begin{array}{c}\text { Below N.A } \\
(\times \mathrm{E}-4)\end{array}$ & $\begin{array}{c}\text { Difference in } \\
\text { strain }\end{array}$ & $\begin{array}{c}\text { Above N.A } \\
(\times \mathrm{E}-4)\end{array}$ & $\begin{array}{c}\text { Below N.A } \\
(\times \mathrm{E}-4)\end{array}$ & $\begin{array}{c}\text { Difference in } \\
\text { strain }\end{array}$ \\
\hline \hline 1 & 100 & 2.61 & 1.81 & 0.80 & 4.89 & 5.43 & 0.54 \\
\hline 2 & 150 & 2.89 & 2.07 & 0.82 & 4.10 & 4.50 & 0.40 \\
\hline 3 & 300 & 4.64 & 3.27 & 0.87 & & & \\
\hline
\end{tabular}




\section{Conclusion}

Designing of any important RCC or PSC flexural structures like bridge girders etc., the time-dependent effects should not only govern by the properties of concrete in use and environmental conditions but it also governed by the percentage area of reinforcement present in the section, its span, and eccentricity of applied pre-stress force. In RCC members the growth of time-dependent strain increases with increase in its span and decreases on increase in percentage area of reinforcement. In PSC members, the increase in eccentricity of pre-stress force increases the growth of timedependent strain. Presence of reinforcement and pre-stress force in concrete flexural members develops non-uniform strain across its depth, which influences growth of sagging deflections in RCC flexural members and hogging deflections in PSC flexural members. The ultimate creep and shrinkage strain values for any particular grade of concrete will be different, depending upon its use weather in RCC or in PSC. Hence, before construction of any important flexural concrete structures, to ascertain its long-term performance a similar single unit mock model is required to be made and monitored for its time-dependent strain growth. The ultimate strain value obtained from the mock model is required to be considered for design calculations of original structure.

\section{Acknowledgments}

This is to acknowledge that, the research findings are based on the granted Project No. OLP 096312, fund by CSIR-Central Mechanical Engineering Research Institute, Durgapur.

\section{Open Access}

This article is distributed under the terms of the Creative Commons Attribution License which permits any use, distribution, and reproduction in any medium, provided the original author(s) and the source are credited.

\section{References}

ACI 209R-92. (1992). Prediction of creep, shrinkage and temperature effects in concrete structures. ACI Manual of Concrete Practice, Part 1. Detroit: ACI.

American Concrete Institute. ACI. (2005). Building code requirements for structural concrete (ACI 318-05) and commentary (ACI R318-05). Michigan: Farmington Hills, pp. 112.

Bischoff, P. H. (2001). Effects of shrinkage on tension stiffening and cracking in reinforced concrete. Canadian Journal of Civil Engineering 28(3), 363-374.

Gribniak, V., Kaklauskas, G., \& Bacinskas, D. (2007). State-ofart review on shrinkage effect on cracking and deformations of concrete bridge elements. The Baltic Journal of Road and Bridge Engineering 2(4),183-193.

Gribniak, V., Kaklauskas, G., et al. (2008). Shrinkage in reinforced concrete structures: A computational aspect. Journal of Civil Engineering and Management 14(1), 49-60.

Sato, R., et al. (2007). Flexural behavior of reinforced recycled concrete beam. Journal of Advanced Concrete Technology $5(1), 43-61$.

Weiss, W. J. (1999). Prediction of early-age shrinkage cracking in concrete $(\mathrm{PhD}$ dissertation, Northwestern University, 1999). p. 277

Zamblauskaite, R., Kaklauskas, G., \& Bacinskas, D. (2005). Deformation analysis of pre-stressed high strength concrete member using flexural constitutive model. Journal of Civil Engineering and Management 11(2), 145-151

Zuanfeng, P., Zhitao, L., \& Chung, C. F. (2011). Experimental study on creep and shrinkage of high-strength plain concrete and reinforced concrete. Journal of Advances in Structural Engineering 14(2), 235-248. 